\title{
¿Cómo pondera el beneficio-costo de un TLC con USA?
}

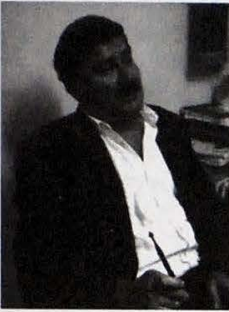

Roberto Rublo, FUNDE

Los tratados de libre comercio son las reglas del juego que indican como se regulará el comercio, que por cierto, no son tan libres, porque son regulaciones que traen perdedores y ganadores. El interés de un pais debe ser el que hayan más ganadores que perdedores. Los problemas de las ventajas y desventajas del tratado tienen que ver con la calidad de ese tratado. Hasta ahora, hemos podido analizar que en el sector agropecuario se tendrán importantes sectores perdedores, sobre todo, en el rubro agroalimentario, que son básicamente los secrores campesinos. Posiblemente los productores de queso para exportación se beneficien. El balance es complejo, como FUNDE lo hemos analizado y tal como se ha negociado, generará bastantes perdedores en ese sector. Por eso, bajo esas condiciones, no debería ser ratificado.

En un tratado no solo debe revisarse la calidad del texto redactado, sino también la calidad de la estructura socio-económica que va a recibir ese tratado. Los productores potenciales de estos rubros, pequeños y medianos, se ven en dificultades porque las exigencias fitosanitarias son muy altas y sólo aquellos que pueden invertir en sanidad animal o vegetal podrán acceder. Posiblemente sean sólo los que ya cuentan con esa capacidad. En otras palabras, si la estructura es muy desigual, tiene canales que privilegian solamente a unos y las oportunidades se canalizan más hacia algunos sectores, entonces, no se aprovechará adecuadamente el tratado.

?

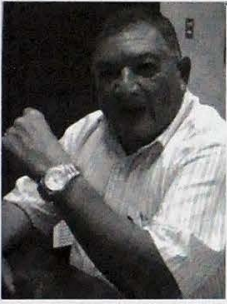

La teoría del comercio internacional sostiene que el comercio entre países permite mejorar los niveles de bienestar de las poblaciones de los países involucrados. Si el tratado con los Estados Unidos va a traer a la población salvadoreña una mejor calidad de vida, mayores empleos, un desarrollo de las micro y pequeñas empresas, una reducción de la pobreza, mayores niveles educativos y de calidad, y otras condiciones con las que se mide el desarrollo, no cabe duda que habrá mayores beneficios que costos para la población. De lo contrario, pues ni hablar.

Jorge Barraza lbarra

UTEC

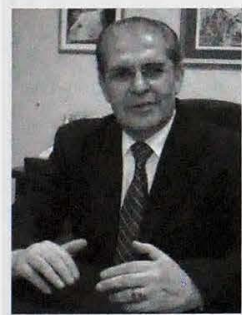

El beneficio neto de un tratado comercial con USA en el mediano plazo es más por el lado de la generación de empleo, transferencia de tecnología y de la inversión extranjera directa, que como exportación neta y como ayuda sustancial en la mejora de la balanza comercial del país. Tendrán que darse cambios apreciables en las formas de producir por parte del sector productivo (modernizar la planta productiva), avances en la estrategia social antes mencionada y acciones concretas: en materia de seguridad personal, seguridad juridica y marco institucional para que ese beneficio se concretice y se amplie a la mayoría de la población. El desplazamiento de pequeñas y medianas empresas con baja capacidad productiva y poca accesibilidad a asistencia técnica es un costo que se percibe también en el mediano plazo.

Rafael Rodríguez Loucel, UTEC 


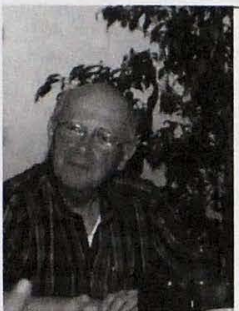

Héctor Dada Hirezl, Diputado COU
Un tratado de libre comercio no es bueno o malo en sí mismo. Hay que conocer el texto para poder juzgarlo. Hay que tener presente que estamos negociando con un pais que no sólo es económicamente muchísimo más grande que nosotros, y con un estadio de desarrollo muy superior, sino también es una economía en la que la intervención del Estado para proteger áreas de la producción (la agricultura por ejemplo)tiene una gran importancia en la determinación de las condiciones del comercio.

Como dice el informe Comisión Económica para América Latina y el Caribe y Sistema de la Integración Centroamericana (CEPAL-SICA), no es sólo por firmar el TLC que se va a tener automáticamente una dinámica de desarrollo, aún en las mejores condiciones surgidas de la negociación del texto. Se requiere de una política de desarrollo para esas puertas que se abririan se aprovechen y para que se minimicen los riesgos. Hasta ahora no creo que se ha discutido una política de respaldo a la transformación tecnológica de los empresarios, que en ciertos casos debe partir de un cambio de giro productivo, con todo lo que ello implica de interacción entre sector empresarial, sector laboral y sector público en su amplia comprensión.

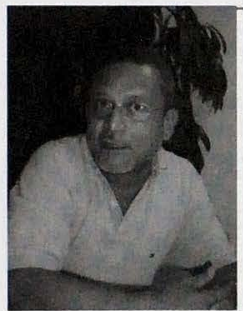

Carlos Briones, FLACSO
El TLC es algo que no he seguido con mucha rigurosidad. Hay ciertas cosas que son favorables para Estados Unidos, pero pienso que nosotros debemos tener la capacidad de visualizar qué oportunidades se nos crean y estar claros de las debilidades que hemos aceptado.

Si creo que el sector agrícola nacional puede ser afectado, pero también nos puede crear un acceso a un mercado más grande, $y$ un nexo más fácil con la comunidad de salvadoreños residenres en ese país, y su éxito dependerá de la estrategia de comercio que se establezca con ellos. Hay que crear una estrategia de comercialización y aprovechar hasta el límite las oportunidades que se nos pueden presentar con el TLC.

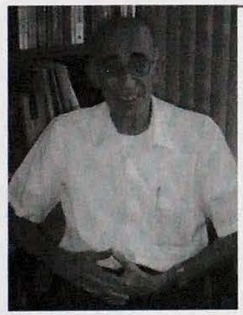

Javier Iblsate,

UCA
Personalmente he tratado de seguir un poco este proceso y - en razón de la brevedad- me remito a tres breves comentarios: (ECA, octubre 2003: "CAFIA: El tratado de libre comercio entre EEUU y Centroamérica" Otton Solis, ministro de planificación de Costa Rica. "La Organización Mundial del Comercio de Cancún: un mundo unilateral" (P. Ibisate. Sale a relucir nuestro TLC) (ECA, enero febrero 2004; "Un Area de Libre Comercio para las Américas (ALCA) a dos velocidades" P. Ibisate. En esos artf́culos expreso mi temor a este TLC, que, gracias a Dios, de momento no se firma. ElTLC con EEUU hay queverlo desde el escenario de la cumbres de la Organización Mundial de Comercio (OMC) en Seattle 1999, Doha Qatar 2001 y Cancún 2003; en todos estos casos se trata del mismo imperio: el libre comercio no es un comercio libre 